\title{
Hiccups leading to dyspnoea in a patient with Covid-19
}

Plínio de Oliveira Holanda 1, 2, 3, José Carlos Rodrigues Nascimento 1, 4, Francisco Thiago Santos Salmito 3, Ingrid Correia Nogueira 3

\author{
${ }^{1}$ Department of Anaesthesia, Instituto Jose Frota, Fortaleza, Brazil. \\ ${ }^{2}$ Department of Anaesthesia, Hospital Regional Unimed Fortaleza, Fortaleza, Brazil. \\ ${ }^{3}$ Unichristus University, Fortaleza, Brazil. \\ ${ }^{4}$ Department of Anaesthesia Hospital Geral de Fortaleza, Fortaleza, Brazil.
}

*Corresponding author: Plínio de Oliveira Holanda. Rua Barbosa de Freitas, nº123 - Fortaleza. Zip Code: 60170 020 Ceara, CE, Brazil. Phone: +55 (85) 32555000. E-mail: anesthesiaceara@gmail.com.

Research Ethics Committee Approval (if necessary): We declare that the patient approved the study by signing an informed consent form and the study followed the ethical guidelines established by the Declaration of Helsinki.

Received on: Jan 12, 2022. Accepted on: Jan 27, 2022. Available online: Jan 28, 2022.

Abstract
In 2020 and 2021, the Covid-19 pandemic caused drastic consequences around the
world. The disease causes a flu syndrome with clinical pictures ranging from mild to
severe. Since it is a systemic flu syndrome, several clinical manifestations have been
described for this disease, but cases of hiccups associated with Covid-19 have rarely
been reported. This report describes a rare case in which a patient with Covid-19
developed respiratory discomfort after complaining of persistent hiccups. The
patient was treated clinically and experienced a sudden improvement in their
dyspnoea immediately after the disappearance of the hiccups crisis. This sudden
improvement suggests a very likely cause-effect relationship.
Keywords: Covid-19; Hiccups; Dispnoea.

\section{Introduction}

Hiccups are characterized by repeated and involuntary diaphragm spasms, followed by rapid and noisy glottis closures. The anatomy of the hiccups reflex is imprecise but may include the vagus and phrenic nerves, branches of the sympathetic thoracic nervous system, brain stem, respiratory centre and intercostal muscles [1]. They are usually acute and self-limiting, but infrequently, hiccups can last more than two days, called persistent, and cases lasting more than one month are 
Hiccups leading to dyspnoea in a patient with Covid-19

characterized as intractable [2]. They are more frequent in male patients [3].

COVID-19 is a highly contagious disease caused by the SARS-COV-2 virus (severe acute respiratory syndrome coronavirus-2) [4], which was initially reported as a severe lung disease in patients in Wuhan, Province of Hubei, China. Cases have been described in which persistent hiccups were associated with COVID-19 [4-7].

Acute hiccups are usually selflimited and harmless [8], but longerlasting events can lead to complications such as arrhythmias and exhaustion, but rarely, hiccups are related to respiratory failure [9]. This is a case study of a male patient who developed a crisis of persistent hiccups, possibly due to complications associated with Covid-19 infection, and this crisis of hiccups probably triggered acute respiratory failure.

\section{Case report}

A 48-year-old ASA 2 (arterial hypertension) man with gastroesophageal reflux was diagnosed with Covid-19 through a positive transcriptase-polymerase chain test (RTPCR) and a computed tomography scan of the chest showing a typical groundglass appearance.

At that time, he was treated with dexamethasone $24 \mathrm{mg} /$ day and azithromycin $500 \mathrm{mg} /$ day. He presented with hiccups on the ninth day after diagnosis, and treatment with chlorpromazine began, but he suspended himself, complaining of drowsiness.

On the eleventh day, he sought emergency care because his oxygen saturation began to vary between $92 \%$ and $94 \%$ in ambient air (monitored by pulse oximetry at home), and because there was no improvement of the hiccups crisis. Upon hospital admission, he complained of hiccups and dyspnoea from minimal exertion and immediately received $\mathrm{O}_{2}$ support of $4 \mathrm{~L} / \mathrm{min}$ in nasal catheter, which maintained his oxygen saturation between $94 \%$ and $95 \%$.

Upon physical examination, the patient presented tachycardia (115 bpm), tachypnoea (30ipm), and crepitations in the middle thirds and bases of both lungs. Chest CT (computed Tomography) identified ground-glass images in $50 \%$ of both lung parenchyma (Figure 1).

After anamnesis, physical examination and results of imaging tests, intravenous ceftriaxone $2 \mathrm{~g}$ was administered every $24 \mathrm{~h}$ plus intravenous dexamethasone $10 \mathrm{mg}$ $12 / 12 \mathrm{~h}$ and bromopride $10 \mathrm{mg}$ orally every six hours. On the second day of hospitalization, treatment with baclofen solution was started at a dose of $10 \mathrm{mg}$ orally every 12 hours.

After 24 hours of treatment with baclofen, there was complete remission of the hiccups and reduction of 
Hiccups leading to dyspnoea in a patient with Covid-19

dyspnoea with improved oxygen saturation $(97 \%)$ without the need for supplemental oxygen. After $48 \mathrm{~h}$ without hiccups, the baclofen therapy was suspended, and on the fifth day, the patient was discharged from the hospital in good clinical condition.
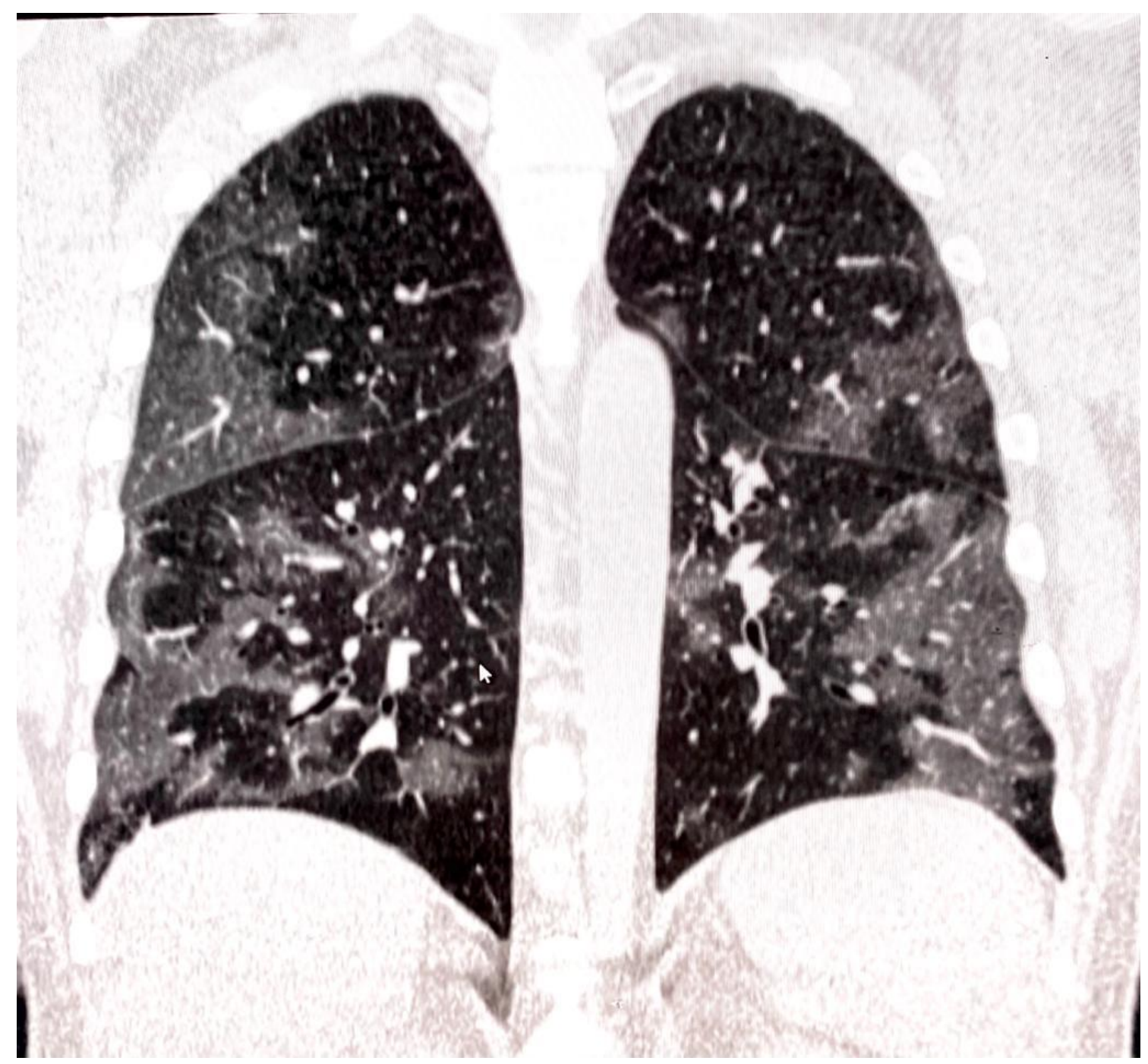

Figure 1. Chest Computed Tomography of the patient.

\section{Discussion and Conclusion}

Hiccups are a rare complication in Covid-19 patients but there are some reports in the literature, most of them in male patients [3]. Usually they appear after respiratory symptoms, but they can be present before these symptoms [10].

Possible causes of hiccups crises are alcohol intake, cigarettes and other irritants of the gastrointestinal or respiratory tract, gastroesophageal reflux, use of corticosteroids, underlying neurological disorders, influenza and 
pneumonia, especially basal cases [8, 11].

In this case, we can highlight as possible causes responsible for the crises gastroesophageal reflux, use of dexamethasone in high doses (24 mg/day), pulmonary pneumonia/ inflammation, or neural involvement caused by Covid-19 [4, 12].

Pneumonia is associated with long-lasting hiccups. One of the causes could be irritation of the phrenic and vague nerves, especially in cases of pneumonia with involvement of the pulmonary bases [2]. Based on physical examination and chest tomography, this patient presented a typical picture of Covid-19 pneumonia with possible bacterial complications, including in the pulmonary bases.

Corticoids are associated with persistent hiccups and dexamethasone is the main cause but the mechanism remains unclear [11]. In general, the doses of dexamethasone that can cause oral reactions range from $8-40 \mathrm{mg}$ [14]. In this case, the patient was treated with a high dose of dexamethasone (24 $\mathrm{mg} /$ day) for five days.

Phrenic nerve damage can lead to hiccups, and there have been reports of phrenic neuropathy in Covid-19 [13]. Some physical maneuvers to relieve hiccups are breath holding, Valsalva's maneuver, drinking cold water etc. These maneuvers are less likely to relieve persistent or intractable hiccups [16].
Various medications have been used for the treatment of hiccups, including bromopride, a dopaminergic antagonist used as an antiemetic; chlorpromazine, an antipsychotic of the phenothiazine group; and baclofen, an antispastic GABA-agonist medication that acts on the GABA-B receptors [1,9]. This patient was treated appropriately with bromopride and baclofen, and his symptoms resolved.

In the present case, the patient presented with dyspnoea with low oxygen saturation and concomitant hiccups. The sudden cessation of dyspnoea soon after the hiccups disappeared strongly suggests a causeeffect relationship, something rarely described [5].

The present case reports a rare situation of persistent hiccups with complaint of dyspnoea lasting over 48 hours in a patient diagnosed with COVID-19. The hiccup crisis may have been triggered by gastroesophageal reflux, the use of high doses of dexamethasone, pneumonia, or even neural compromise from Covid-19 infection. Treatment of the hiccups led to prompt resolution of the dyspnoea.

\section{References}

[1] Eisenächer A, Spiske J. Persistent Hiccups (Singultus) as the Presenting Symptom of Medullary Cavernoma. Deutsches Aerzteblatt Online. 2011;108(48):822-6. 
Hiccups leading to dyspnoea in a patient with Covid-19

[2] Karakonstantis S, Pitsigavdaki S, Korela D, Galani D. Lower lobe pneumonia presenting as singultus (hiccups). Caspian Journal of Internal Medicine. 2018;9(4):403-5.

[3] Nakaya A, Ogura E, Katayama Y, Yoshii M, Yoshino E, Hozumi K, et al. Hiccups as a specific neurological manifestation in males with COVID-19. IDCases [Internet]. 2021;26:e01330.

[4] Deng CX. The global battle against SARS-COV-2 and COVID-19. International Journal of Biological Sciences. 2020;16(10):1676-7.

[5] Ali SK, Muturi D, Sharma K. Be Wary of Hiccups: An Unusual Case of COVID-19. Cureus. 2021 Jan 28.

[6] Ikitimur H, Uysal BB, Ikitimur B, Umihanic S, Smajic J, Jahic R, et al. Case report: Two cases of persistent hiccups complicating COVID-19. American Journal of Tropical Medicine and Hygiene. 2021;104(5):1713-5.

[7] Prince G, Sergel M. Persistent hiccups as an atypical presenting complaint of COVID-19. American Journal of Emergency Medicine. 2020;38(7):1546.e5-1546.e6.

[8] Polito NB, Fellows SE. Pharmacologic Interventions for Intractable and Persistent Hiccups: A Systematic Review. Journal of Emergency Medicine. 2017;53(4):540-9.
[9] Fodstad H, Nilsson S, Fodstad H, Nilsson S. Intractable singultus: A diagnostic and therapeutic challenge. 1993.

[10] Dadras O, Asghari A, Nosratzahi A. Persistent Hiccups as an Atypical Initial Presentation of COVID-19: A Case Report. Infectious Disorders - Drug Targets. 2021 Sep 6;21.

[11] Steger M, Schneemann M, Fox M. Systemic review: The pathogenesis and pharmacological treatment of hiccups. Alimentary Pharmacology and Therapeutics. 2015;42(9):1037-50.

[12] Abubaker AK, Rabadi DK, Kassab M, Al-Qudah MA. Persistent hiccups after cervical epidural steroid injection. American Journal of Case Reports. 2018;19:397-9.

[13] Karampoor S, Afrashteh F, Laali A. Persistent hiccups after treatment of COVID-19 with dexamethasone: A case report. Respiratory Medicine Case Reports [Internet]. 2021;34(September):101515.

[14] Cersosimo RJ, Brophy MT. Hiccups with high dose dexamethasone administration: A case report. Cancer. 1998;82(2):412-4.

[15] Maurier F, Godbert B, Perrin J. Respiratory Distress in SARS-CoV-2 without Lung Damage: Phrenic Paralysis Should Be Considered in COVID-19 Infection. European journal 
of case reports in internal medicine

[Internet]. 2020;7(6):001728.

[16] de Sene DR, Watashi DM, Bilitardo

I de O, Moreno CEC, Moreno MF de F.

Covid-19 presenting as persistent

hiccups: A case report. Revista do

Instituto de Medicina Tropical de Sao

Paulo. 2021;63.

Conflict of interest: The author declares no conflicts of interest associated with this manuscript.

Acknowledgements: None.

Funding: None.

How to cite this article: Holanda PO,

Nascimento JCR, Salmito FTS, Nogueira

IC. Hiccups leading to dyspnoea in a patient with Covid-19. Brazilian Journal of Case Reports. 2022 Jan-Mar;02(1):5964. 